\title{
Comparison of fastrach LMA and ILMA methods for airway management
}

\author{
Mustafa Ozgur Cırık'; Ramazan Baldemir'; Sema Avcı' ${ }^{2}$; Hayal Tezel'; Mustafa Tayfun Aldemir ${ }^{4}$ \\ ${ }^{1}$ Ankara Atatürk Chest Diseases and Chest Surgery Research and Training Hospital, Ankara, Turkey. \\ ${ }^{2}$ Amasya University Sabuncuoglu Serefeddin Research and Training Hospital, Amasya, Turkey. \\ ${ }^{3}$ Istanbul Kartal Research and Training Hospital, Istanbul, Turkey. \\ ${ }^{4}$ Istanbul Kanuni Sultan Suleyman Research and Training Hospital, Istanbul, Turkey.
}

\section{*Corresponding Author (s): Sema Avcı}

Amasya University Sabuncuoglu Serefeddin Research and Training Hospital, Amasya, Turkey.

Tel: +90-530-843-13-63; Email: dnzlsema@gmail.com

Received: Dec 04, 2018

Accepted: Mar 25, 2018

Published Online: Mar 29, 2018

Journal: Annals of Epidemiology and Public health

Publisher: MedDocs Publishers LLC

Online edition: http://meddocsonline.org/

Copyright: (C) Avcı S (2019). This Article is distributed under the terms of Creative Commons Attribution 4.0 International License

Keywords: Intubation; LMA-Fastrach; Airway

\section{Abstract}

The aim of this study is to compare the hemodynamic responses, durations of intubation, intubation success rates and postoperative upper airway complications between the intubation performed with direct laryngoscopy and blind intubation performed with LMA-Fastrach application in normotensive patients. This present study was performed with the approval of ethical committee and in the surgery rooms between the date March 2010-August 2010. The study was performed on 80 patients aged between 18 and 60 and had American Anesthetists Assosiation (ASA) classification I-II. Endotracheal intubation was essential in their elective abdomen surgeries. The patients were divided into 2 groups as ILMA-Fastrach Group (Group I, n=40) and laryngoscopy group (Group $L, n=40$ ). 80 patients aged between 18 and 60 . Of those, 54 (67.5\%) were female and 26 (32.5\%) were male. The age average of the patients was $46.3 \pm 10.7$. There was not a statistically significant difference between the demographic parameters of the patients. When compared to the onset value of SAP in Group I and Group L, a statistically significant difference was not detected in the groups in terms of SAP $1^{\text {st }}$ minute and $5^{\text {th }}$ minute values. When compared to the SAP onset value of the cases, the decrease in the $1^{\text {st }} \mathrm{min}$ ute was statistically significant and when compared to the $1^{\text {st }}$ minute value, the decrease in the $5^{\text {th }}$ minute was not statistically significant. In the groups, a statistically significant difference was not observed in terms of DAP outset $1^{\text {st }}$ and $5^{\text {th }}$ minute values. When compared to the DAP onset value of the patients in Group $L$, the increase in the $1^{\text {st }}$ minute was statistically significant. When compared to the $1^{\text {st }}$ minute value, the decrease in the $5^{\text {th }}$ minute was statistically significant. When compared to the onset value of MAP in Group $L$, the increase in the $1^{\text {st }}$ minute was statistically significant. In terms of HR onset $1^{\text {st }}$ and $5^{\text {th }}$ minute values a statistically significant value was not detected. In conclusion, patients performed endotracheal intubation with LMA-Fastrach was more stabile than the ones intubated with direct laryngoscopy in terms of hemodynamics. Fewer complications were observed in LMA-Fastrach group and there was not any difference in terms of success rates.

Cite this article: Cırık MO, Baldemir R, Avcı S, Tezel H, Aldemir MT. Comparison of fastrach LMA and ILMA methods for airway management. A Epidemiol Public Health. 2019; 2(1): 1006. 
Introduction

Endotracheal intubation performed during general anesthesia provides many advantages such as maintenance of airway patency and safety, respiratory control, less effort for respiration, less dead space and decreased aspiration risks [1,2]. However, laryngoscopy and endotracheal intubation develop a sympathetic reflex response based on the mechanical stimulation of the larynx and trachea; this sympathetic response may cause increase in plasma catechalemine levels, tachycardia, hypertension, arthymia and myocardial ischemia especially in patients with limited heart reserve [3]. The generated temporary hyperdynamic response may cause severe complications in patients with aort aneurysm, recent myocard infarctus history, cerebral aneurysm and intracranial hypertension [4]. Nevertheless, the application of layrngeal mask does not stimulate layrngeal reflexes as much as laryngoscopy does, and its cardiovascular response is more restricted when compared with laryngoscopy [5]. Although many laryngeal masks (LMA) are being used for airway safety, Fastrach LMA or intubation LMA (ILMA) has been specially designed for easing endotracheal intubation and maintains the ventilation [6]. The primary advantage of ILMA designed by Dr. A.I.J. in 1997 is that it does not necessitate head and neck manipulation during the application and the practitioner does not need to place their finger into the patient's mouth $[7,8]$.

The aim of this study is to compare the hemodynamic responses, durations of intubation, intubation success rates and postoperative upper airway complications between the intubation performed with direct laryngoscopy and blind intubation performed with LMA-Fastrach application in normotensive patients.

\section{Material and method}

This present study was performed with the approval of ethical committee in the surgery rooms of Bezm-i Alem Vakıf Gureba Training and Research Hospital between the date's March 2010-August 2010. The study was performed on 80 patients aged between 18 and 60 and had American Anesthetists Association (ASA) classification I-II. Endotracheal intubation was essential in their elective abdomen surgeries. The patients were divided into 2 groups as ILMA-Fastrach Group (Group I, n=40) and laryngoscopy group (Group L, n=40). Informed consents of all the patients included in the study were obtained before the operation.

The study excluded the patients in ASA III classification and the risk group over this, the ones whose planned operation time was over 2 hours, the ones who had allergy history and respiratory and central nervous system diseases, gastroesophageal reflux, hypertension, head and neck surgery history, the ones who were experienced to have difficulty in establishing cooperation. Besides, the patients were evaluated in terms of difficult intubation and the patients with difficult intubation history, Mallampati score 3 and 4 , the ones whose mouth opening was below 2 $\mathrm{cm}$ and morbid obese patients were not included in the study. Physical examination of the patients was done one day before the operation. Thiromental distance and sternomental distance was measured. Length, weight and Mallampati scores of all patients were recorded. Before the operation in the waiting room the patients were provided vascular access on their antecubular region or dorsum of the hand with $20 \mathrm{G}$ intravenous cannula and they were started to be intravenously (i.v) given crystalloid fluid at $2 \mathrm{ml} / \mathrm{kg} /$ hour pace. All patients were premedicated with $0.02 \mathrm{mg} / \mathrm{kg}$ i.v midazolam with the aim of premedication. In the operating room patients were lying supine position and Electrocardiography (ECG), heart rate (HR), systolic arterial blood pressure (SAP), diastolic arterial blood pressure (DAP), mean arterial blood pressure (MAP) and peripheric oxygen saturation (sPO2) were monitorized.

Before the induction, the patients were pre-oxygenized with $100 \%$ oxygen for three minutes. In the induction, while the patients were given 5-7 mg/kg thiopental sodium, $1 \mu \mathrm{cgr} / \mathrm{kg}$ fentanyl and $0.5 \mathrm{mg} / \mathrm{kg}$ and rocuronium i.v, ventilation was provided with a mask for 3 minutes. In the Fastrach group ILMA size for patients in 70-100-kilogram $(\mathrm{kg}$ ) range was identified as 5 size, endotracheal tube was identified as 8.0 Internal Diameter (ID). For the patients in the range of $50-70 \mathrm{~kg}$, ILMA size 4 and endotracheal tube 7.5 ID were identified. Before ILMA was placed to the oropharynx, water based lubricate gel was spreaded on the surface. It was placed to the oropharynx with rotation movement when the patient's head was in the neutral position. Size 5 ILMA cuff was inflated with 40 mililitre $(\mathrm{ml})$ air. Size 4 ILMA cuff was inflated with $30 \mathrm{ml}$ air. The followings were aimed with manual ballon ventilation; to measure end-tidal $\mathrm{CO}_{2}$ value in capnography, to see the movement of chest wall, to maintain no air leek and to provide the measured airway pressure to be lower than $25 \mathrm{~cm} \mathrm{H}_{2} \mathrm{O}$. In the contrary case, rotation in the sagittal plane and little manipulations right to left and forward to backward were done. Despite manipulations, if ILMA still was not in the right position, the process was accepted to be unsuccessful. ILMA was removed from the mouth and with a second try it was replaced to the oropharynx. After the process was confirmed to be successful, endotracheal tube was pulled through ILMA and the tube cuff without an air leak was inflated with the volume of air that the producing company suggested. Endotracheal tube position was confirmed with capnography and the appearance of the movement of the bilateral chest wall. After the confirmation of the tube placement, the air in the ILMA cuff was aspirated and the ILMA was removed from the mouth. The time of the process was recorded as the total time from unpacking ILMA to removing it from the mouth.

In the direct laryngoscopy group, the size of the endotracheal tube was identified as 8.0 ID for the patients in the range of 70-100 kilogram $(\mathrm{kg})$. For the patients in the range of 50-70 $\mathrm{kg}$, the size was determined as 7.5ID. Before the laryngoscopy, the head was softly taken to extention position. The mouth was opened, and endotracheal tube was intubated by using Macintosh laryngoscopy. With no air leak, endotracheal tube cuff was inflated with volume of air the producing company's suggested. The placement of the endotracheal tube was confirmed with capnography and the appearance of bilateral chest wall movement. The duration of the process was recorded as the time from unpacking the tube to removing it from the mouth. In each group, the followings were recorded: numbers and times of trials, whether or not any bleeding occurred in the tube or mucosa, whether or not the patients were saturated. All the applications of ILMA and larygoscopy were performed with the same person. In the maintaince of the anesthesia in every group $50 \% \mathrm{O}_{2}, 50 \% \mathrm{~N}_{2} \mathrm{O}$ and 2-3\% sevoflurane was used. MAP, DAP, $\mathrm{HR}$ and $\mathrm{SpO}_{2}$ values of the patients were measured in the $1^{\text {st }}$ and $5^{\text {th }}$ minutes before the anesthesia induction and following the induction. All the patients were administered i.v tramadol $1 \mathrm{mg} /$ $\mathrm{kg}$ five minutes before the anesthesia was terminated. Anesthetic gases were turned down five minutes before the surgery was ended and the patients were given $100 \%$ oxygen. Decurarisation was provided with neostigmine $0.02 \mathrm{mg} / \mathrm{kg}$ and atropine 


\section{$0.01 \mathrm{mg} / \mathrm{kg}$ i.v.}

The patients were assessed after extubation for whether or not any mucosal bleeding and tooth damage occurred. Then, they were taken to the recovery room. In the $2^{\text {nd }}$ hour of the postoperation, sore throat and hoarseness were questioned. For the check of pharyngolaryngeal morbidity, sore throat and hoarseness were evaluated with 4-point scale.

\section{Sore throat;}

Level 1: Absence Level. 2: Less than common cold. Level 3: Similar to a common cold. Level 4: Very severe.

\section{Hoarseness;}

Level 1: Absence. Level 2: Only the patient feels. Level 3: Both the patient and the listener feel. Level 4: Severe aphonia.

\section{Statistical analysis}

Findings obtained in the study were evaluated for statistical analysis with the use of the program SPSS (Statistical Package for Social Sciences) for Windows 17.0. In addition to the descriptive statistical methods (mean, standart deviation, frequency, percent), Kolmogorov-Smirnov test was also used for the examination of the normal distribution. In comparison of the quantitive parameters and within group comparisons of the normally distributed parameters, Independent Samples t test was used. In within-group comparisons of normally distributed parameters, Repeated Measures Anova was used. In within-group comparisons of the parameters, Bonferroni Post Hoc test was used. In comparisons of the quantitive parameters, $\mathrm{Q}$-square test was used. The results were evaluated in the range of $95 \%$ realiability and the significany was evaluated as $p<0.05$.

\section{Results}

This present study was performed on totally 80 patients aged between 18 and 60. Of those, 54 (67.5\%) were female and 26 (32.5\%) were male. The age average of the patients was $46.3 \pm$ 10.7. The length average of them was $163.5 \pm 6.6 \mathrm{~cm}$ (154 -178 $\mathrm{cm})$; the weight average was $77.7 \pm 13.4 \mathrm{~kg}(50-116 \mathrm{~kg})$. According to the groups, there was not a statistically significant difference between the demographic parameters of the patients ( $p$ $>0.05$ ), (Table 1).

Table 1: Distribution of the demographic features according to the groups

\begin{tabular}{|c|c|c|c|}
\hline & $\begin{array}{c}\text { Group L (40) } \\
\text { Mean } \pm \text { sd }\end{array}$ & $\begin{array}{c}\text { Group I (40) } \\
\text { Mean } \pm \text { sd }\end{array}$ & P \\
\hline Age (year) & $45.1 \pm 11.6$ & $47.6 \pm 9.8$ & 0.316 \\
\hline Body Weight (kg) & $76.6 \pm 15.8$ & $78.8 \pm 10.5$ & 0.470 \\
\hline Length (cm) & $164.4 \pm 6.6$ & $162.7 \pm 6.7$ & 0.276 \\
\hline Gender (F/M) & $24 / 16$ & $30 / 10$ & 0.152 \\
\hline ASA (I/II) & $25 / 15$ & $24 / 16$ & 0.818 \\
\hline
\end{tabular}

Age, weight and length parameters were stated as \pm standart deviation, gender and ASA classification were stated as \%. ASA: American Society of Anesthesiologists, F: female, M: male, Group L: Laryngoscopy group, Group I: LMA fast-trach group.
Table 2: Distribution of intubation trials according to the groups

\begin{tabular}{|c|c|c|c|}
\hline & Group L (n/\%) & Group I (n/\%) & P \\
\hline 1.Trial & $39 / 97.5$ & $38 / 95$ & 0.500 \\
\hline 2.Trial & $1 / 2.5$ & $2 / 5$ & 0.500 \\
\hline
\end{tabular}

The number of intubation trials was stated as \%. Group L: Laryngoscopy group, Group I: LMA fast-trach group.

Table 3: Distribution of intubation trial times based on the groups

\begin{tabular}{|c|c|c|c|}
\hline & Group L & Group I & P \\
\hline Trial time (min) mean $\pm \mathrm{sd}$ & $18.8 \pm 7.1$ & $49.2 \pm 27.8$ & $0.000^{*}$ \\
\hline
\end{tabular}

* $p<0.05$ : Between the groups. Trial times were stated as \pm standart deviation. Group L: Laryngoscopy group, Group I: LMA fast-trach group, sd: standart deviation.

One patient in the Group $L$ and two patients in the Group I became successful in the second trial and it was not statistically significant ( $p>0.05$ ), (Table 2 ). Trial times (49.2 min.) of the patients in Group I was found to significantly higher than the trial times (18.8 min.) in Group L $(p<0.01)$, (Table 3). When the groups were compared in terms of hoarseness, hoarseness level 1 was observed in 8 patients in Group $L$ and three patients in Group I. In Group I, one patient was observed to have hoarseness at level 2 and this was not statistically significant ( $p$ $>0.05$ ).

When the groups were compared in terms of sore throat, in Group L in 8 patients level 1 sore throat, in four patients level 2 sore throat was observed. In Group I, in two patients level 1, in three patients level 2 and in 1 patient level 4 sore throat was observed. However, it was not statistically significant $(p>0.05)$.

When compared to the onset value of SAP in Group I and Group L, a statistically significant difference was not detected in the groups in terms of SAP $1^{\text {st }}$ minute and $5^{\text {th }}$ minute values $(p>0.05)$.

When compared to onset value of SAP of the patients in Group $L$, the increase in the $1^{\text {st }}$ minute was not statistically significant $(p<0.05)$ and when compared with the increase in the $1^{\text {st }}$ minute, the decrease in the $5^{\text {th }}$ minute was statistically more significant $(p<0.05)$. When compared to the SAP onset value of the cases, the decrease in the $1^{\text {st }}$ minute was statistically significant $(p<0.05)$ and when compared to the $1^{\text {st }}$ minute value, the decrease in the $5^{\text {th }}$ minute was not statistically significant $(p>0.05)$.

In the groups, a statistically significant difference was not observed in terms of DAP outset $1^{\text {st }}$ and $5^{\text {th }}$ minute values $(p>$ 0.05).

When compared to the DAP onset value of the patients in Grup $L$, the increase in the $1^{\text {st }}$ minute was statistically significant. When compared to the $1^{\text {st }}$ minute value, the decrease in the $5^{\text {th }}$ minute was statistically significant $(p<0.05)$. Compared to the DAP onset value of the patients in Grup I, the decrease in the $1^{\text {st }}$ minute was not statistically significant. Compared to the $1^{\text {st }}$ minute value, the decrease in the $5^{\text {th }}$ minute was not statistically significant $(p>0.05)$. Mean artery pressure (MAP) onset value in Group I and Group L did not show a statistically significant difference in terms of $1^{\text {st }}$ minute and $5^{\text {th }}$ minute values $(p>0.05)$. 
When compared to the onset value of MAP in Group $L$, the increase in the $1^{\text {st }}$ minute was statistically significant. When compared to the $1^{\text {st }}$ minute value, the decrease in the $5^{\text {th }}$ minute was statistically significant $(p<0.05)$.

When compared to the MAP onset value of the patients in Group I, the decrease in the $1^{\text {st }}$ minute was statistically significant $(p<0.05)$ but compared to the $1^{\text {st }}$ minute value, the decrease in the $5^{\text {th }}$ minute was not statistically significant $(p>0.05)$.

In terms of HR onset $1^{\text {st }}$ and $5^{\text {th }}$ minute values a statistically significant value was not detected $(p>0.05)$.

When compared to the HR onset value in Group L, the increase in the $1^{\text {st }}$ minute was not statistically significant. Compared to the $1^{\text {st }}$ minute value, the decrease in the $5^{\text {th }}$ minute was not statistically significant ( $p>0.05$ ). When compared to the HR onset value of the patients in Group I, the decrease in the $1^{\text {st }}$ minute was not statistically meaningful. Compared to the $1^{\text {st }}$ minute value, the decrease in the $5^{\text {th }}$ minute was not statistically significant $(p>0.05)$.

\section{Discussion}

This present study, comparing LMA-Fastrach and direct laryngoscopy with endotracheal intubation, demonstrated that a rise in cardiovascular response did not occur in the patients applied Fastrach LMA; MAP and DAP values were observed to be increased in the patients applied direct laryngoscopy. Undesired complications such as a rise in Heart Rate (HR), hoarseness and sore throat were more frequently experienced in the patients applied direct laryngoscopy. In every group, first trial of intubation rate success was high. Direct laryngoscopy and tracheal intubation are known as the golden standart in providing the safety and maintanence of airway patency [9]. During direct laryngscopy, plasma catecholamine concentration increases because of the pressure applied to the supraglottic tissues. Correspondingly, an increase in the hemodynamic response is observed. Especially in hypertensive patients this response is more severe, continues in a longer time and may be resulted in myocardial ischemia, arrhythmia and cerebrovascular damage $[5,10,11]$. For that reason, an endotracheal intubation technique to be resulted with minimal hemodynamic flactuation is essential [12]. Additionally, it is necessary that the success rate of the intubation should be high, intubation should be performed in an acceptable time and complication rate should be low. ILMA suggests a new approach for endotracheal intubation [13]. Shetty et al. [14] in their study performed clinical evaluation of endotracheal intubation. They successfully performed intubation in $96 \%$ of the patients. They also found successful intubation rate as 56\%. Zhang et al. [15] in their study planned to perform LMA-Fastrach on 28 patients. They had success on 24 patients in the first trial of the intubation, 3 patients in the second trial and 1 patient in the third trial.

In another study performed, it was detected that the success rate of the blind intubation with ILMA was $83.3 \%, 13.3 \%$, $3.3 \%$ respectively in the first, second and third trials [16]. Baskett et al. [17] in their study performed on 500 patients used LMA-Fastrach for intubation and were able to be successful in $79.8 \%$ of the patients in the first trial, in $12.2 \%$ of them in the second trial and in $4 \%$ of them in the third trial. They were not able to intubate 19 patients. In 17 of the 19 patients not having been intubated, the reason of the failure can be explained with not being used to the technique for the first 20 patients. In our study, successful intubation was performed at the rate of $95 \%$ in the first trial. In the second trial, 2 patients' intubation was performed successfully. When compared with the literature data, the success in the first trial of intubation was higher in our study. Timmermann et al. [18] performed a study with 30 intern doctors who did not have any experience in airway techniques. In the study, they compared ambu mask with ventilation, laryngoscopic tracheal intubation and LMA-Fastrach with intubation. The success was detected as $92.2 \%$ with LMA-Fastrach intubation, and $60 \%$ with laryngoscopy with endotracheal intubation. Success rate in LMA-Fastrach with blind intubation in the first trial was $83 \%$ whereas it was $42 \%$ in the laryngoscopic tracheal intubation. In this study, medicine students were more successful in the application of LMA-Fastrach. In the training programs held for medical personnel inexperienced in airway and paramedics, it was stated that LMA-Fastrach could be preferred to traditional airway manegenment techniques [18].

In another study where intubation with LMA fastrach were evaluated, it was found that the time for placement of the endotracheal tube with LMA-Fastrach was approximately 35.85 seconds [19]. Zhang et al. in their study demonstrated that intubation time performed with LMA-Fastrach was three times more when compared with intubation with laryngoscopy. In our study, intubation time in Group I was 2.5 times longer than Group $L$ and this time was determined as 49.2 seconds. In the study, although the practitioner was experienced in intubation with laryngoscopy, they had their first experience in this study after they learned the right technique for ILMA application. The length of time can be based on the inexperience of the practitioner and abundance of control and application steps of ILMA compared with direct laryngoscopy.

Intubation with LMA-Fastrach consists of 3 steps; placement of LMA-Fastrach and confirmation of the place, placement of the endotracheal tube and confirmation of its place, removal of LMA-Fastrach from its place. For that reason, longer time of intubation with LMA-Fastrach compared with laryngoscopy is an expected result.

The literature shows quite different results associated with hemodynamic responses to intubation under the guidance of ILMA. Some studies showed that endotracheal intubation under the guidance of ILMA and direct laryngoscopy also caused similar hemodynamic results. It was observed that ILMA did not provide a statistical advantage in hemodynamic parameters in terms of SAP, DAP, MAP, HP; in every group there was an increase in these parameters after the intubation and there was not any difference between the groups [15, 16, 20-22]. Another study showed that there was a statistically significant but clinically insignificant increase based on the basal values of HR and MAP after the intubation with ILMA [23]. Additionally, it was detected that these results were in compliance with some other studies performed [14, 24, 25].

Hemodynamic response depends on the the size of the airway, duration of appliance and the duration of apnea. For that reason, minimum stimulation of the orofarengeal structures necessitates a meticulous technique and permanent ventilation [26]. Yadav et al. [26] in their study stated that intubation under the guidance of ILMA was a blind technique and this necessitated great manipulations. In their study, they compared endotracheal intubation with C-Trach LMA providing direct visibility and direct laryngoscopy. It was stated that C-Trach LMA provided direct visibility; laryngeal entrance was able to be visualized and it caused fewer manipulations. However, SAP, DAP, MAP and HR values were observed to be inceased right after 
the intubation, HR and SAP was observed to be significantly increased in the direct laryngoscopy group [26]. This present study detected that intubation with ILMA had positive results hemodynamically when compared to the direct laryngoscopy. Success rate in the first trial in the ILMA group was quite high. When in the first trial success was not still obtained even after small manipulations, second trial was performed. In ILMA application great manipulations were not performed. For that reason, we think that hemodynamic parameters were not affected. Mean trial duration was higher compared with direct laryngoscopy, though. When adequent pre-oxygenization was not provided, we observed that this did not negatively affect hemodynamics, which showed an acceptable apnea time. Additionally, after laryngeal mask was placed before endotracheal intubation, provision of ventilation for to confirm placement of ILMA shortened apnea time.

Baskett et al. [17], in their study performed on 500 patients, observed that HR and blood pressure increased following the placement of LMA-Fastrach, a significant increase occurred in heart rate and blood pressure after the blind intubation [17]. In our study, even though HR was not statistically significant after endotracheal intubation, it showed decrease in LMA-Fastrach group whereas it increased in laryngoscopy group. Blood pressure values following the intubation showed a decrease compared to the values prior to the induction in LMA group. This is because LMA causes fewer stimulations on oropharyngeal area compared to the laryngoscopy.

Kihara et al. [27] in their study compared direct laryngoscopy "light wand" and LMA-Fastrach with hemodynamic response to the intubation in normotensive and hypertensive patients [27]. In normotensive patients, differency between the groups in terms of hemodynamic responses were not observed. In hypertensive patients, SAP and DAP was observed to be significantly increased in laryngoscopy group [27]. Another study demonstrated that in ILMA group after the intubation $1^{\text {st }}$ minute DAP value was significantly lower in normotensive patients when compared to the other groups [12]. In our study, differing from the study of Kihara et al. [27] in the laryngoscopy group following the intubation in the $1^{\text {st }}$ minute a significant increase occurred in DAP. In LMA -Fastrach group following the intubation, the decrease in SAP and MAP in the $1^{\text {st }}$ minute was significant. Increased hemodynamic response observed in hypertensive patients during the direct laryngoscopy may be thought to be associated with sensitivity increased to catecholamines. Joo et al. [28] in their study compared blind intubation with LMA-Fastrach, fiberoptic assisted intubation with LMA-Fastrach and direct laryngoscopy with endotracheal intubation. They obtained equal results for sore throat and hoarseness in three groups. Kihara et al. [29], in their upper airway studies, determined that the high pressure effect of LMA-Fastrach's metallic structure on mucosa caused an increase of pharyngolaryngeal morbidity in postoperative period [29]. However, differing from our study, in this study Fastrach was kept in its placement during the operation. In our study, Fastrach- LMA was used as an intubation tool and was not kept in its place along the preoperative period. In our study, an increase in pharyngolaryngeal morbidity was not observed in patients intubated with Fastrach-LMA in the postoperative period when compared to the ones intubated with laryngoscopy. Fastrach was developed for to provide endotracheal intubation under the guidance of laryngeal mask. Fastrach -LMA should be removed keeping the endotracheal tube in its place. Otherwise, as seen in the studies, mucosal damage and postoperative pharyngolarnegeal morbidity may increase.
Consequently, patients performed endotracheal intubation with LMA-Fastrach was more stabile than the ones intubated with direct laryngoscopy in terms of hemodynamics. Fewer complications were observed in LMA-Fastrach group and there was not any difference in terms of success rates. For these reasons, laryngoscopy can be an alternative to laryngoscopy application. However, this idea needs to be supported with more studies to be done with larger groups.

\section{References}

1. Davis L, Cook-Sather SD, Schreiner MS. Lighted stylet tracheal intubation: A Review. Anesth Analg. 2000; 90: 745-756.

2. Atkinson RS, Rushman GB, Davies NJH. Editors. In: Lee's Synopsis of Anaesthesia. ELBS with Butterworth- Heinemann. 1993; 217238.

3. Shribman AJ, Smith G, Achola KJ. Cardiovascular and catecholamine responses to laryngoscopy with and without tracheal intubation. Br J Anaesth. 1987; 59: 295-299.

4. Thomson IR. The haemodynamic response to intubation: A perspective. Can J Anaesth. 1989; 36 :367-369.

5. Jarineshin $\mathrm{H}$, Kashani S, Vatankhah M, Abdulahzade Baghaee A, Sattari $S$, et al. Better hemodynamic profile of laryngeal mask airway insertion compared to laryngoscopy and tracheal intubation. Iran Red Crescent Med J. 2015; 17.

6. Henderson JJ, Popat MT, Latto IP, Pearce AC; Difficult Airway Society. Difficult Airway Society guidelines for management of the unanticipated difficult intubation. Anaesthesia. 2004; 59: 675-694.

7. Brain Al, Verghese C, Addy EV, Kapila A. The intubating laryngeal mask I: Development of a new device for intubation of trachea. Br J Anaesth. 1997; 79: 699-703.

8. Brain Al, Verghese C, Addy EV, Kapila A, Brimacombe J. The intubating laryngeal mask-II: A preliminary clinical report of a new means of intubating the trachea. Br J Anaesth. 1997; 79: 704709.

9. Martin C, Nefzger T, Lotz G. [Atemwegsmanagement - alternatives atemwegsmanagement im rettungsdienst]. AINS-Anästhesiologie Intensivmedizin Notfallmedizin Schmerztherapie. 2016; 51: 254-262.

10. Bennett SR, Grace D, Griffin S.C. Cardiovascular changes with the larngeal mask airway in cardiac anaesthesia. British Journal of Anaesthesia. 2004; 92: 885-887.

11. Choyce A, Avidan MS, Harvey A, Patel C et al. The cardiovascular response to insertion of the intubating laryngeal mask airway. Anaesthesia. 2002; 57: 330-333.

12. Gvalani SK, Mane S. Comparison of haemodynamic responses in normotensive and hypertensive patients among three intubation devices: macintosh laryngoscope, intubating laryngeal mask airway and lightwand. Int J Res Med Sci. 2016; 4: 38583864.

13. Choudhary B, Karnawat R, Mohammed S, Gupta M, Srinivasan $B$, et al. Comparison of Endotracheal Intubation Through I-gel and Intubating Laryngeal Mask Airway. The Open Anesthesiology Journal. 2016; 18-24.

14. A Shetty, P Shroff, L Chaudhari, R Prashanth. Clinical Appraisal of Intubating Laryngeal Mask Airway (ILMA) for blind endotracheal intubation in the patients undergoing Spine or Orthopaedic Surgery under General Anaesthesia. The Internet Journal of Anesthesiology. 2005; 10: 1-6. 
15. Zhang GH, Xue FS, Sun HY, Li CW, Sun HT, et al. Comparative study of hemodynamic responses to orotracheal intubation with intubating laryngeal mask airway. Chin Med J (Engl) 2006; 119 899-904.

16. Kavitha J, Tripathy DK, Mishra SK, Mishra G, Chandrasekhar LJ, Ezhilarasu P. Intubating condition, hemodynamic parameters and upper airway morbidity: A comparison of intubating laryngeal mask airway with standard direct laryngoscopy. Anesth Essays Res. 2011; 5: 48-56.

17. Baskett PJF, Parr MJA, Nolan P. The intubating laryngeal mask. Anaesthesia. 1998; 53: 1174-1179.

18. Timmermann A, Russo SG, Crozier TA, Eich C, Mundt Be, $t$ al. Novices Ventilate and Intubate Quicker and Safer via Intubating Laryngeal Mask than by Conventional Bag-Mask Ventilation and Laryngoscopy. Anesthesiology 2007; 107: 570-576.

19. Siamdoust SS, Rokhtabnak F, Motlagh SD, Rahimzadeh P, Hassani $\mathrm{V}$, et al. Comparison of the Success Rate of Intubation Between the LMA Fastrach and AirQ-ILA Methods in Patients Undergoing Elective Surgery During General Anaesthesia. Anesth pain med. 2018 August; 8: e63424.

20. Zhang Guo - hua, XUE Fu -shan, SUN Hai, Li Cheng -wen, SUN Hai -tao, et al. Comparative study of hemodynamic responses to orotracheal intubation with intubating laryngeal mask airway and direct laryngoscopy; Chinese Medical Journal 2006; 119: 899-904.

21. J Kavitha, Dependra Kumar Tripathy, Sandeep Kumar Mishra, Gayatri Mishra et al. Intubating condition, hemodynamic parameters and upper airway morbidity: A comparison of intubating laryngeal mask airway with standard direct laryngoscopy; Anaesthesia Essays and research 2011;15: 48-56.

22. Choyu A, Avidan MS, Harvey A, Patel C, Timberlake C, et al. The cardiovascular response to insertion of the intubating laryngeal mask airway. Anaesthesia. 2002; 57: 330-333.
23. Sandhya A. Bakshi, Pradeep Kumar HG, Vrishali R Ankalwar, Naresh G Tirpude. Our Experiences with Intubating Laryngeal Mask Airway for Endotracheal Intubation. Journal of Evidence based Medicine and Healthcare. June 2015; 2: 3893-3904.

24. Baskett PJ, Parr MJ, Nolan JP. The Intubating Laryngeal Mask. Results of a multicentre trial with experience of 500 cases. Anaesthesia. 1998; 53: 1174-1179.

25. Asai T, Wagle AU, Stacey M. Placement of the intubating laryngeal mask is easier than the laryngeal mask during manual inline neck stabilization. Br J Anaesth. 1999; 82: 712-714.

26. Deepti Yadav, Sadik Mohammed, U D Sharma, Rakesh Karnawat, Ghansham Biyani. Comparison of intubation by LMA CTrach vs Intubation by direct laryngoscopy in patient with normal airway. Indian Journal of Clinical Anaesthesia. 2014; 1: 4-12.

27. Kihara S, Brimakombe J, Yaguchi Y. Hemodynamic responses among three tracheal intubation devices in normotensive and hypertensive patients. Anesth Analg. 2003; 96: 890-895.

28. Joo HS, Rose DK. The intubating laryngeal mask airway with and without fiberoptik guidance. Anesth Analg 1999; 88: 662-666.

29. Kihara S, Yaguchi Y. Routine use of the intubating laryngeal mask airway results in increased upper airway morbidity. Can J Anesth. 2001; 48: 604-608. 